\title{
Fuzzy sliding mode power control for wind power generation systems connected to the grid
}

\author{
Imane El Karaoui ${ }^{1}$, Mohamed Maaroufi ${ }^{1}$, Badre Bossoufi ${ }^{2}$ \\ ${ }^{1}$ Department of Electrical Engineering, Mohammadia School of Engineers, Mohammed V University, Rabat, Morocco \\ ${ }^{2}$ LIMAS Laboratory, Faculty of Sciences Dhar El Mahraz, Sidi Mohammed Ben Abdellah University, Fez, Morocco
}

\begin{tabular}{l} 
Article Info \\
\hline Article history: \\
Received May 19, 2021 \\
Revised Jan 31, 2022 \\
Accepted Feb 7, 2022 \\
\hline
\end{tabular}

Keywords:

Doubly fed induction

generation

Fuzzy logic

Fuzzy sliding mode control

Maximum power point tracking

algorithm

Sliding mode

Wind turbine

\begin{abstract}
In recent years we have witnessed a real increase in the production of wind turbines and wind farm installations around the world, in order to improve this own energy, several studies have focused on the interest of controlling the active and reactive power of the system. Wind power, and at the same time on the quality of the energy produced and its connection in order to ingest suitable electrical energy into the distribution network. This article studies a new control technology to meet the various constraints in the field. The objective for work is to develop and study the sliding mode control method applied to a wind power system based on doubly fed induction generation (DFIG), as well as an optimization using the fuzzy logic technique. Ensuring the stability of the system is one of the objectives of using the Lyapunov nonlinear technique in the sliding mode control strategy which will be applied to the two converters (machine side and network side). The proposed solution was to validate a simulation on MATLAB/Simulink, tracking test (true wind speed) and also the robustness of the system.
\end{abstract}

This is an open access article under the CC BY-SA license.

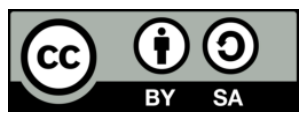

\section{Corresponding Author:}

Imane El Karaoui

Department of Electrical Engineering, Mohammadia School of Engineers (EMI),

Mohammed V University

Rabat, Morocco

Email: elkaraoui.imane@gmail.com

$\begin{array}{lll}\text { NOMENCLATURE } \\ \text { WPGS } & : \text { Wind power generation system } \\ \mathrm{DFIG} & : \text { Doubly fed induction generator } \\ \mathrm{P}_{\mathrm{R}} & : \text { Power ricovred by the wind turbine } \\ \mathrm{P}_{\mathrm{vent}} & : \text { Kinetic wind power } \\ \mathrm{C}_{\mathrm{p}} & : \text { Power coefficient } \\ \mathrm{Tr} & : \text { Aerodynamic torque } \\ \mathrm{V}_{\mathrm{ds}}, \mathrm{V}_{\mathrm{qs}} & : \text { Stator voltage } \\ \mathrm{V}_{\mathrm{dr}}, \mathrm{V}_{\mathrm{qr}} & : \text { Rotor voltage } \\ \mathrm{I}_{\mathrm{ds}}, \mathrm{I}_{\mathrm{qs}} & : \text { Stator current }\end{array}$

$\begin{array}{lll}\mathrm{I}_{\mathrm{dr}}, \mathrm{I}_{\mathrm{qr}} & : & \text { Rotor Current } \\ \varphi_{\mathrm{ds}}, \varphi_{\mathrm{qs}} & : & \text { Stator flux } \\ \varphi_{\mathrm{dr}}, \varphi_{\mathrm{qr}} & : & \text { Rotor Flux } \\ \mathrm{Ps} & : & \text { Active Stator Power } \\ \mathrm{Qs} & : & \text { Reactive Stator Power } \\ \mathrm{Pr} & : & \text { Active Rotor Power } \\ \mathrm{Qr} & : & \text { Reactive Rotor Power } \\ \text { Tem } & : & \text { Electromechanical torque }\end{array}$

\section{INTRODUCTION}

In recent decades, the massive industrialization caused the hard increase of electrical energy consumption. The forecasts of energy needs for the coming years only confirm this. Finding different 
sustainable solutions is necessary to meet the future word energy needs [1]-[3]. In the immediate future, the world experiences a recourse to renewable energies, which present inexhaustible resources. Among which we find wind energy identified as one of the most promising for achieving greenhouse gas emission reduction targets. The exploitable renewable energies are numerous and varied. That said, the development of wind energy is booming, so wind systems are developing more quickly because we can now rely on reliable and proven techniques with better performance.

Wind energy therefore remains the most used in energy production technique, hence the case of Morocco, which relies on wind energy production as the primary source of renewable energy with $4699.4 \mathrm{GWh}$ in 2019 against 1581, $50 \mathrm{GWh}$ for solar and it is considered the country's second energy source against $32,218.50$ for thermal energy, i.e. a rate of $11.7 \%$ of the country's total energy production [3], [4]. The Figure 1 shows the graphic of energy production in Morocco.

Currently, the majority of wind turbine installations in the world used DFIG- Generator. Because this type of machine has the ability to produce electric power at variable speed. The control of the studied system based on double-fed machines by classical methods (proportional, integral and derivative action) implies the knowledge of the various parameters, which can influence it and allow the system to achieve the set results. In addition, the strongly coupled variables, increasing the system, makes control more difficult. Using nonlinear methods is one of the solution to solve this problem like the sliding mode controller (SMC) control. The latter is considered one of the simplest approaches to control nonlinear systems and systems with imprecise models [5]-[10].
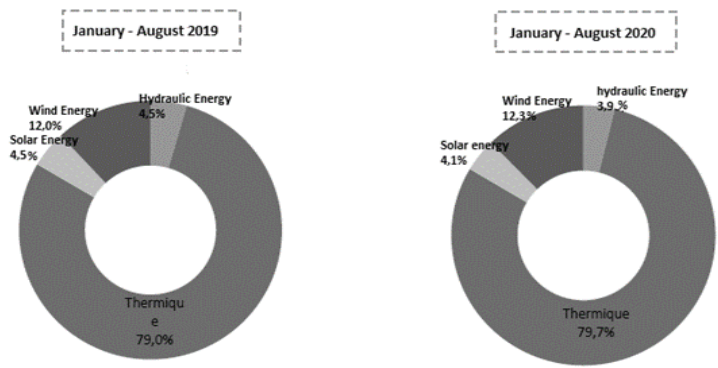

Figure 1. Graphical representation of energy production in Morocco

\section{WIND ENERGY CONVERSION SYSTEMS (WECS) MODEL}

The Figure 2 presents the wind energy structure. It contains the doubly fed induction generator, the converter, the filter and the grid. The control is showing in the input of the converter.

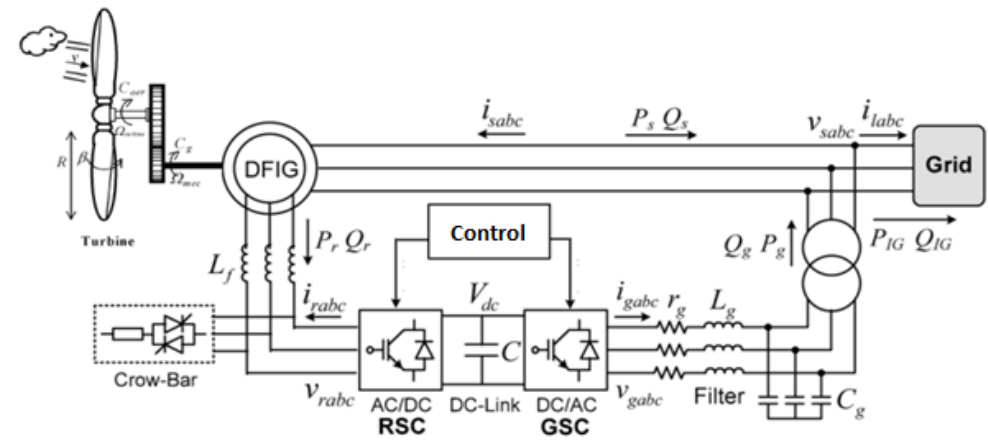

Figure 2. WECS structure

\subsection{Resource modeling}

\subsubsection{Resources potential}

The equation for the wind power recoverable by the wind turbine is [10]-[13]:

$$
P_{R}=P_{\text {vent }} \cdot C_{p}(\lambda, \beta)
$$


The total kinetic power in the wind turbine is:

$$
\begin{gathered}
P_{\text {vent }}=\frac{1}{2} \rho S v^{3} \\
P_{R}=\frac{1}{2} \rho S . C_{p}(\lambda, \beta) v^{3}
\end{gathered}
$$

For the production of wind turbines, it is necessary to take into account the defined range of the energy extraction coefficient which is generally between 0.35 and 0.5 .

$$
\begin{aligned}
& \mathrm{C}_{\mathrm{p}}(\lambda, \beta)=\mathrm{c}_{1} \cdot\left(\mathrm{c}_{2} \cdot \frac{1}{\mathrm{~A}}-\mathrm{c}_{3} \cdot \beta-\mathrm{c}_{4}\right) \cdot \mathrm{e}^{-\mathrm{c}_{5 \frac{1}{\mathrm{~A}}}+\mathrm{c}_{6} \cdot \lambda} \\
& \frac{1}{A}=\frac{1}{\lambda+0.08 \cdot \beta}-\frac{0.035}{1+\beta^{3}} \\
& \lambda=\frac{\Omega_{t} \cdot R}{V}
\end{aligned}
$$

The equation of the aerodynamic torque (Tr) whose coefficient curves.

$$
\mathrm{T}_{\mathrm{r}}=\frac{\mathrm{P}_{\mathrm{r}}}{\Omega_{\mathrm{t}}}=\frac{1}{2} \rho S \cdot \mathrm{C}_{\mathrm{p}}(\lambda, \beta) \mathrm{v}^{3} \cdot \frac{1}{\Omega_{\mathrm{t}}}
$$

The following two equations used to model the adaptation of the two turbine speeds to that of the generator.

$$
\begin{aligned}
& \Omega=\mathrm{G} \cdot \Omega_{\mathrm{t}} \\
& \mathrm{T}_{\mathrm{r}}=\mathrm{G} \cdot \mathrm{T}_{\mathrm{m}} \mathrm{q} \\
& \mathrm{J} \frac{\mathrm{d} \Omega}{\mathrm{dt}}=\mathrm{T}_{\mathrm{m}}-\mathrm{T}_{\mathrm{em}}-\mathrm{f} . \Omega
\end{aligned}
$$

It is necessary to have a simulation tool capable of modeling the entire energy conversion chain and predicting its performance. Initially, a model of the wind generator is proposed under MATLAB/Simulink to evaluate its dynamics and its performance under different operating parameter changes. Figure 3 shows the model of bloc turbine in MATLAB/Simulink.

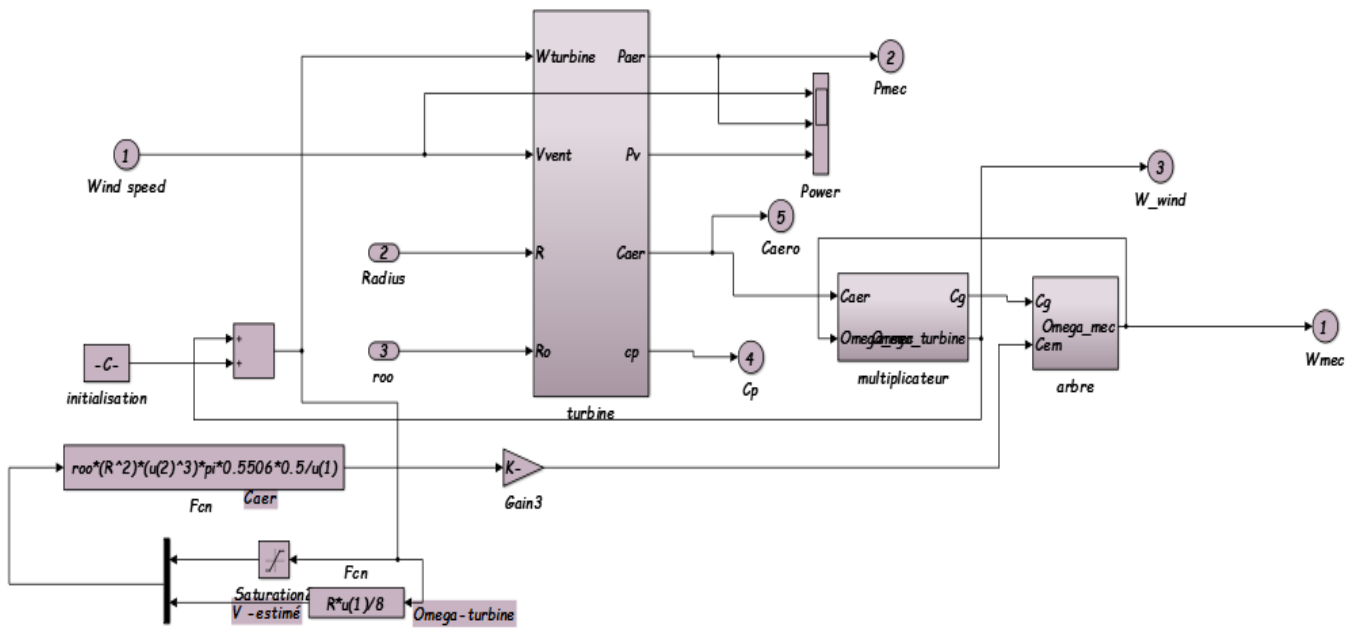

Figure 3. Turbine model

\subsection{Pitch control and mechanical control}

In order to better control the operation of the machine, a number of parameters must be defined beforehand on which the operation and behavior of the machine depends, such as: 
- The wind speed which allows defining the parametric changes of the machine,

- The nominal power $P_{n}$ on the wind turbine shaft,

- The speed reference $v_{n}$ which corresponds to the power $P_{n}$

- The starting speed $v_{d}$ is the minimum wind speed can start to operate and provide energy.

- The safety speed $v_{m}$ is the wind speed which when it is exceeded the wind turbine automatically stops working.

The turbine operating power diagramed is divided into four zones defined according to the wind speed $\mathrm{Vn}, \mathrm{Vd}$ and $\mathrm{Vm}$ witch presented in Figure 4 the first zone corresponds to $\mathrm{P}=0$ the turbine is not yet working. The second zone corresponds to the phase where the power supplied depends on the wind speed. The third is when the supplied power stabilizes at Pn for a constant speed of rotation and in the end the fourth zone which corresponds to the stopping of the energy transfer for safety reasons [14]-[19]

Figure 5 shown the turbine has greater efficiency for low stall angle values. A single control loop may be sufficient to control the pitch for angle $\beta$ to manage the orientation of the wind turbine blades. The rated power is controlled by a single servo loop and which is read with an open loop for controlling the orientation of the blades or the output of the first is the values of the pitch angle of the second. and therefore, we have two servo loops, one for nominal power control the second is for wedging angle control.

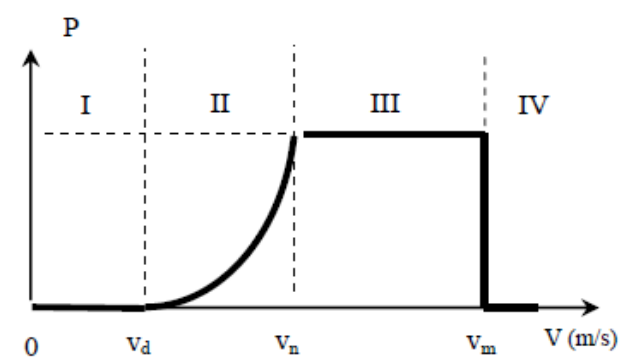

Figure 4. The turbine operating power diagramed

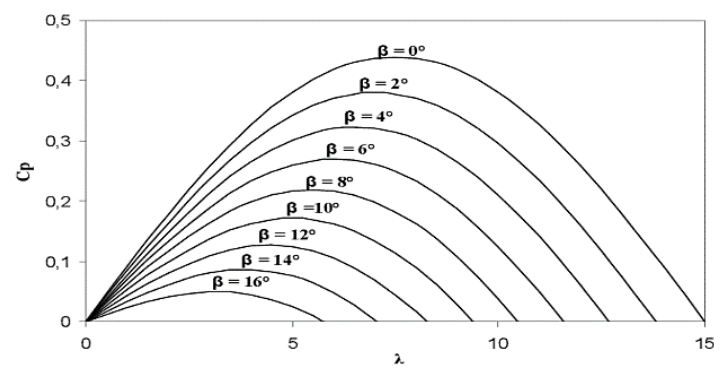

Figure 5. Pitch angle influence

\subsection{Power control technic}

In order to limit the extracted power from the turbine so that it is equal to the nominal power of the generator, two principles of aerodynamic control can be used [20]-[24]: he first is the "pitch control" or not variable "which is based on the rotation of the blades by electric or hydraulic actuators which makes it possible to adjust the pitch angle $\beta$, which is called the blade orientation mechanism. it is therefore a principle which allows the mechanical adjustment of the turbine in order to keep it at its maximum efficiency.

The second principle is the "aerodynamic stall" considered more robust and the simples. The moment when the wind speed exceeds the nominal speed of rotation of the turbine, a suction thus created by the inclination of the blades which will not be in the same optimal position leads to a reduction in the power coefficient. Therefore, this inclination limits the increase in the speed of rotation. The interest of the first check can be observed from Figure 6.

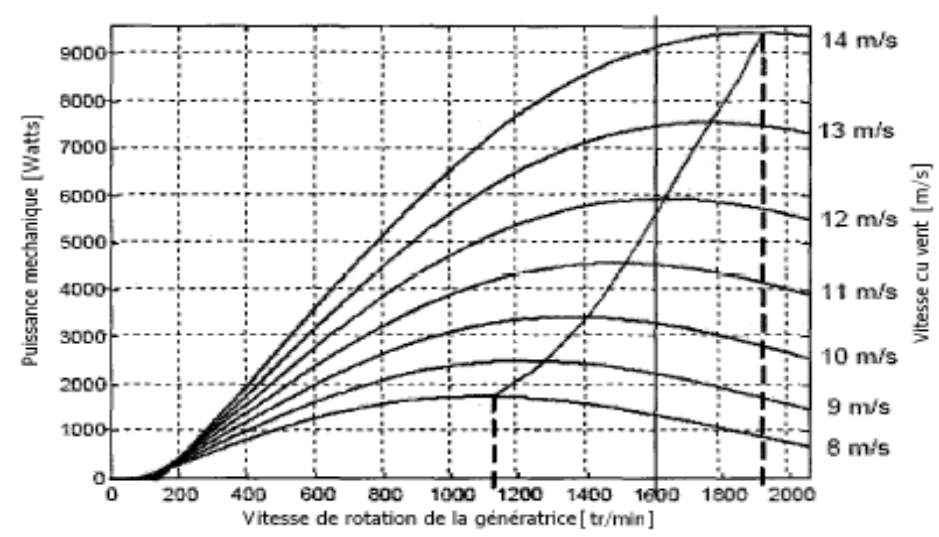

Figure 6. Power of a turbine 


\subsection{Generator modeling}

The generator we used for wind power conversion is the dual-feed asynchronous generator DFIG. [25]-[27]. The DFIG Model is schematized in Figure 7 is a in the park referential model, using the following equations:
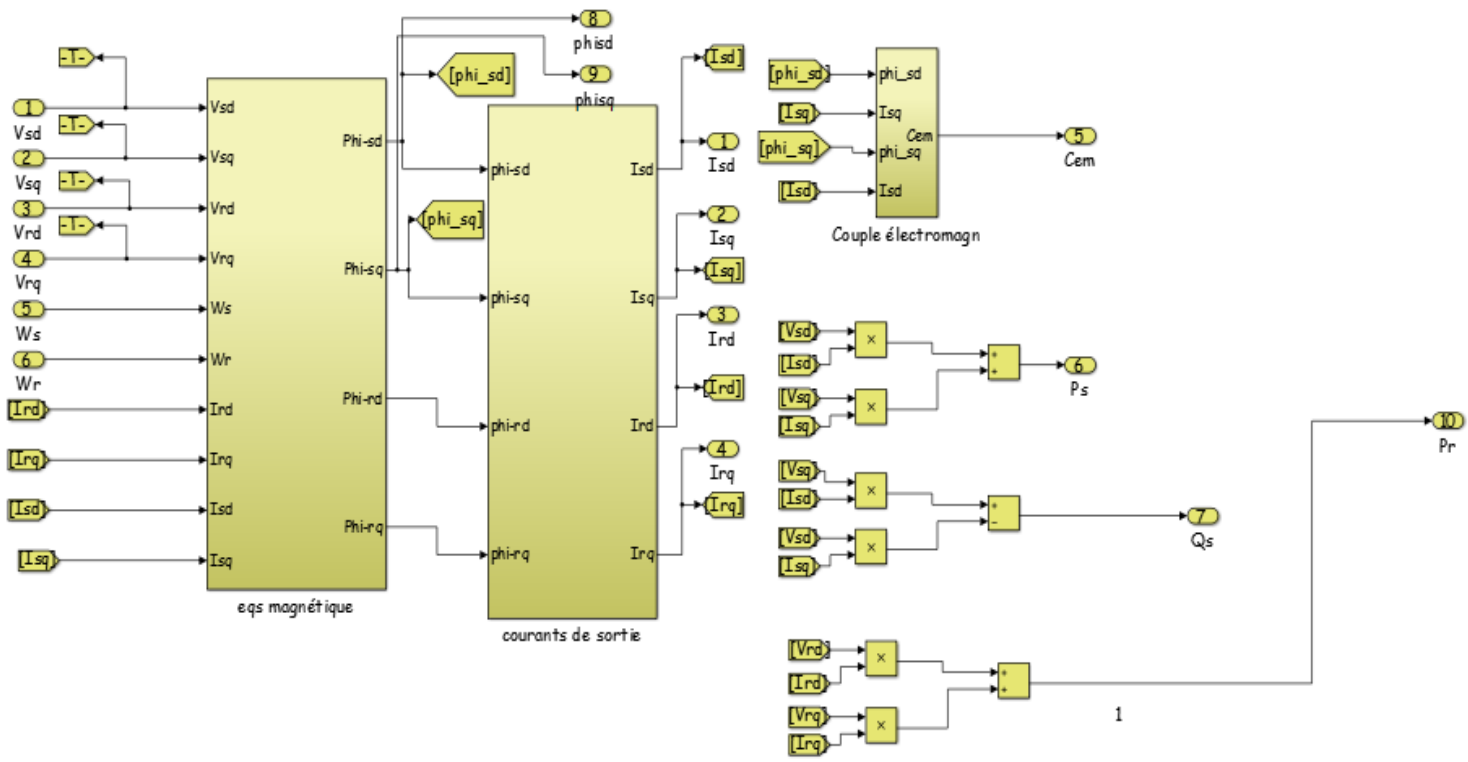

Figure 7. DFIG model

\subsubsection{Stator and rotor voltage}

The following equations define respectively. The stator and rotor voltage related to stator and rotor flux. We use in this definition park referential.

$$
\begin{aligned}
\mathrm{V}_{\mathrm{ds}} & =\mathrm{R}_{\mathrm{s}} \mathrm{I}_{\mathrm{ds}}+\frac{\mathrm{d} \varphi_{\mathrm{ds}}}{\mathrm{dt}}-\theta_{\mathrm{s}} \varphi_{\mathrm{qs}} \\
\mathrm{V}_{\mathrm{qs}} & =\mathrm{R}_{\mathrm{s}} \mathrm{I}_{\mathrm{qs}}+\frac{\mathrm{d} \varphi_{\mathrm{qs}}}{\mathrm{dt}}-\theta_{\mathrm{s}} \varphi_{\mathrm{ds}} \\
\mathrm{V}_{\mathrm{dr}} & =\mathrm{R}_{\mathrm{r}} \mathrm{I}_{\mathrm{dr}}+\frac{\mathrm{d} \varphi_{\mathrm{dr}}}{\mathrm{dt}}-\theta_{\mathrm{r}} \varphi_{\mathrm{qr}} \\
\mathrm{V}_{\mathrm{qr}} & =\mathrm{R}_{\mathrm{r}} \mathrm{I}_{\mathrm{qr}}+\frac{\mathrm{d} \varphi_{\mathrm{qr}}}{\mathrm{dt}}-\theta_{\mathrm{r}} \varphi_{\mathrm{dr}}
\end{aligned}
$$

\subsubsection{Stator and rotor currents}

Using the park referential. We define the following equations respectively. The stator and rotor current related to stator and rotor flux

$$
\begin{aligned}
& \mathrm{I}_{\mathrm{ds}}=\frac{1}{\sigma \cdot \mathrm{L}_{\mathrm{s}}} \cdot \varphi_{\mathrm{ds}}-\frac{\mathrm{M}}{\sigma \cdot \mathrm{L}_{\mathrm{r}}} \cdot \varphi_{\mathrm{dr}} \\
& \mathrm{I}_{\mathrm{qs}}=\frac{1}{\sigma \cdot \mathrm{L}_{\mathrm{s}}} \cdot \varphi_{\mathrm{qs}}-\frac{\mathrm{M}}{\sigma \cdot \mathrm{L}_{\mathrm{s}} \cdot \mathrm{L}_{\mathrm{r}}} \cdot \varphi_{\mathrm{qr}} \\
& \mathrm{I}_{\mathrm{dr}}=\frac{1}{\sigma \cdot \mathrm{L}_{\mathrm{r}}} \cdot \varphi_{\mathrm{dr}}-\frac{\mathrm{M}}{\sigma \cdot \mathrm{L}_{\mathrm{r}}} \cdot \varphi_{\mathrm{ds}} \\
& \mathrm{I}_{\mathrm{qr}}=\frac{1}{\sigma \cdot \mathrm{L}_{\mathrm{r}}} \cdot \varphi_{\mathrm{qr}}-\frac{\mathrm{M}}{\sigma \cdot \mathrm{L}_{\mathrm{s}} \cdot \mathrm{L}_{\mathrm{r}}} \cdot \varphi_{\mathrm{qs}}
\end{aligned}
$$

\subsubsection{Stators and rotor flux}

In the same referential dq we will define. The stator flus related to stator and rotor currents. The rotor flux related to stator and rotor currents and the electromagnetic torque relative to rotation speed

$$
\begin{aligned}
\varphi_{\mathrm{ds}} & =\mathrm{L}_{\mathrm{s}} \mathrm{I}_{\mathrm{ds}}+\mathrm{MI}_{\mathrm{dr}} \\
\varphi_{\mathrm{qs}} & =\mathrm{L}_{\mathrm{s}} \mathrm{I}_{\mathrm{qs}}+\mathrm{MI}_{\mathrm{qr}} \\
\varphi_{\mathrm{dr}} & =\mathrm{L}_{\mathrm{r}} \mathrm{I}_{\mathrm{dr}}+\mathrm{MI}_{\mathrm{ds}}
\end{aligned}
$$




$$
\begin{aligned}
& \varphi_{\mathrm{qr}}=\mathrm{L}_{\mathrm{r}} \mathrm{I}_{\mathrm{qr}}+\mathrm{MI}_{\mathrm{qs}} \\
& \mathrm{T}_{\mathrm{em}}=\mathrm{T}_{\mathrm{r}}+\mathrm{f} \Omega+\mathrm{J} \frac{\mathrm{d} \Omega}{\mathrm{dt}}
\end{aligned}
$$

\subsubsection{Stator and rotor powers}

The (13) describe the active and reactive power of the stator in a two-phase reference system relative to current and voltage. The active and reactive power of the rotor in a two-phase reference system relative to current and voltage.

$$
\begin{aligned}
& \mathrm{P}_{\mathrm{s}}=\frac{3}{2}\left(\mathrm{~V}_{\mathrm{ds}} \cdot \mathrm{I}_{\mathrm{ds}}+\mathrm{V}_{\mathrm{qs}} \cdot \mathrm{I}_{\mathrm{qs}}\right) \\
& \mathrm{Q}_{\mathrm{s}}=\frac{3}{2}\left(\mathrm{~V}_{\mathrm{qs}} \cdot \mathrm{I}_{\mathrm{ds}}+\mathrm{V}_{\mathrm{ds}} \cdot \mathrm{I}_{\mathrm{qs}}\right) \\
& \mathrm{P}_{\mathrm{r}}=\frac{3}{2}\left(\mathrm{~V}_{\mathrm{dr}} \cdot \mathrm{I}_{\mathrm{dr}}+\mathrm{V}_{\mathrm{qr}} \cdot \mathrm{I}_{\mathrm{qr}}\right) \\
& \mathrm{Q}_{\mathrm{r}}=\frac{3}{2}\left(\mathrm{~V}_{\mathrm{qr}} \cdot \mathrm{I}_{\mathrm{dr}}+\mathrm{V}_{\mathrm{dr}} \cdot \mathrm{I}_{\mathrm{qr}}\right)
\end{aligned}
$$

\subsubsection{DFIG model}

The following equations determine the electromechanical torque Figure 7.

$$
\mathrm{T}_{\mathrm{em}}=\mathrm{p}\left(\mathrm{I}_{\mathrm{ds}} \cdot \varphi_{\mathrm{qs}}-\mathrm{I}_{\mathrm{qs}} \cdot \varphi_{\mathrm{ds}}\right)
$$

The reference frame used is the $\mathrm{d}-\mathrm{q}$ reference frame related to the rotating field of the stator, and by considering the hypothesis for the generators used in wind energy the resistance of the stator will be neglected, this said the equation of the torque will be:

$$
\mathrm{T}_{\mathrm{em}}=\mathrm{p} \frac{\mathrm{M}}{\mathrm{L}_{\mathrm{s}}}\left(\varphi_{\mathrm{ds}} \cdot \mathrm{I}_{\mathrm{qr}}-\varphi_{\mathrm{qs}} \mathrm{I}_{\mathrm{dr}}\right)
$$

\section{SLIDING-MODE-CONTROL APPLIED TO THE DFIG}

This method consists in first determining the adequate sliding surface, as well as the equivalent and non-linear value for each quantity to be regulated [27]-[29].

\subsection{Sliding surfaces}

$$
\dot{x}=f(x, t)+B(x, t) \cdot u(x, t)
$$

Is a representation of a non lineair système

$$
\begin{aligned}
& x \in R^{n} \\
& f(x, t) \in R^{n}, \quad B(x, t) \in R^{n * m}, u \in R^{m}
\end{aligned}
$$

$\mathrm{f}$ and $\mathrm{g}$ are two continuous nonlinear functions uncertain and bounded Considering the "J. J Slotine" equation, the sliding surface [28] is:

$$
S(x)=\left(\frac{d}{d t}+\delta\right)^{n-1} \cdot e(x)
$$

where:

$e=x_{d}-x$

$\delta$ : Positive coefficient;

$e$ : Error to be regulated;

$n$ : System order.

$x_{d}$ : Desired variable

This command is based on the principle to keep the surface at zero, so we can have just one solution of the differential equation $e(x)=0$.

\subsection{Conditions of convergence}

The convergence condition is defined by the lyapunov equation [29].

$$
\mathrm{V}(\mathrm{x})=\frac{1}{2} \cdot \mathrm{S}(\mathrm{x})^{2}>0
$$




\subsection{Determination of the control law}

The command $(u)$ is a variable structure command and the control algorithm is defined by the relation [29].

$$
\begin{aligned}
& u=\left\{\begin{array}{l}
u^{+}(x), s(x, t)>0 \\
u^{-}(x), s(x, t)<0
\end{array}\right. \\
& \mathrm{U}=\mathrm{U}_{\mathrm{eq}}+\mathrm{U}_{\mathrm{n}}
\end{aligned}
$$

Where:

$u^{-} \neq u^{+}$Where $u^{+}$and $u^{-}$: continuous functions

The derivative of the surface $S(x)$ is:

$S(x)=\frac{\partial S}{\partial t} \cdot f(x)+\frac{\partial S}{\partial t} \cdot B(x) \cdot U_{e q}+\frac{\partial S}{\partial t} \cdot B(x) \cdot U_{n}$

$\mathrm{U}_{\mathrm{eq}}=-\frac{\partial \mathrm{S}}{\partial \mathrm{t}} \cdot \mathrm{f}(\mathrm{x}) \cdot\left(\frac{\partial \mathrm{S}}{\partial \mathrm{t}} \cdot \mathrm{B}(\mathrm{x})\right)^{-1}$

So $\frac{\partial S}{\partial t} \cdot B(x) \neq 0$,

By in $S(x)$

$\mathrm{S}(\mathrm{x})=\frac{\partial \mathrm{S}}{\partial \mathrm{t}} \cdot \mathrm{B}(\mathrm{x}) \cdot \mathrm{U}_{\mathrm{n}}$

Considering the attractiveness condition $S(x) . S(x)^{\bullet}<0$, the sign $U_{n}$ will be opposed to $\frac{\partial S}{\partial t}$. $B(x) \cdot S(x)$

Different form existed in the literature [28], like $U_{n}=K \cdot \operatorname{sign}(S(x))$

$K:$ Positive constant

(sign): the classical sign function.

The saturation function can be expressed by [27], [28]:

$$
\operatorname{sat}(\varphi)\left\{\begin{array}{c}
1 \text { if } \varphi>\varepsilon \\
-1 \text { if } \varphi<\varepsilon \\
\frac{\varphi}{\varepsilon} \text { if }|\varphi| \leq \varepsilon
\end{array}\right.
$$

\subsection{The sliding mode application}

This part is devoted to the application of the control by sliding mode in the asynchronous generator with double feed. Following the new considerations, the previous become as such:

$$
\begin{aligned}
& \mathrm{v}_{\mathrm{sd}}=0 \\
& \mathrm{v}_{\mathrm{sq}}=\mathrm{v}_{\mathrm{s}}=\omega_{\mathrm{s}} \cdot \emptyset_{\mathrm{s}} \\
& \mathrm{v}_{\mathrm{rd}}=\mathrm{R}_{\mathrm{r}} \cdot \mathrm{I}_{\mathrm{rd}}+\frac{\mathrm{d} \emptyset_{\mathrm{rd}}}{\mathrm{dt}}+\omega_{\mathrm{r}} \cdot \emptyset_{\mathrm{rq}} \\
& \mathrm{v}_{\mathrm{rq}}=\mathrm{R}_{\mathrm{r}} \cdot \mathrm{I}_{\mathrm{rq}}+\frac{\mathrm{d} \emptyset_{\mathrm{rq}}}{\mathrm{dt}}+\omega_{\mathrm{r}} \cdot \emptyset_{\mathrm{rd}} \\
& \mathrm{P}_{\mathrm{s}}=-\mathrm{V}_{\mathrm{s}} \cdot \frac{\mathrm{M}}{\mathrm{L}_{\mathrm{s}}} \cdot \mathrm{I}_{\mathrm{rq}} \\
& \mathrm{Q}_{\mathrm{s}}=\frac{\mathrm{v}_{\mathrm{s}}{ }^{2}}{\omega_{\mathrm{s}} \cdot \mathrm{L}_{\mathrm{s}}}-\mathrm{V}_{\mathrm{s}} \cdot \frac{\mathrm{M}}{\mathrm{L}_{\mathrm{s}}} \cdot \mathrm{I}_{\mathrm{rd}} \\
& \dot{\mathrm{I}}_{\mathrm{rd}}=\frac{\mathrm{v}_{\mathrm{rd}}}{\mathrm{L}_{\mathrm{r}} \cdot \sigma}-\frac{\mathrm{R}_{\mathrm{r}}}{\mathrm{L}_{\mathrm{r}} \cdot \sigma} \cdot \mathrm{I}_{\mathrm{rd}}+\omega_{\mathrm{r}} \cdot \mathrm{I}_{\mathrm{rq}} \\
& \dot{\mathrm{I}}_{\mathrm{rq}}=\frac{\mathrm{v}_{\mathrm{rq}}}{\mathrm{L}_{\mathrm{r}} \cdot \sigma}-\frac{\mathrm{R}_{\mathrm{r}}}{\mathrm{L}_{\mathrm{r}} \cdot \sigma} \cdot \mathrm{I}_{\mathrm{rq}}-\omega_{\mathrm{r}} \cdot \frac{\mathrm{M} \cdot \mathrm{v}_{\mathrm{s}}}{\mathrm{L}_{\mathrm{s}} \cdot \mathrm{L}_{\mathrm{r}} \cdot \sigma \cdot \omega_{\mathrm{s}}}
\end{aligned}
$$




\section{ACTIVE POWER CONTROL SURFACE}

Considering the sliding surface by J. Slotine given by:

$$
\mathrm{S}(\mathrm{x})=\left(\frac{\mathrm{d}}{\mathrm{dt}}+\delta\right)^{\mathrm{n}-1} \mathrm{e}(\mathrm{x})
$$

We consider $n=1$,

We have the active power control surface the:

$$
\begin{aligned}
& \mathrm{S}\left(\mathrm{P}_{\mathrm{S}}\right)=\mathrm{e}\left(\mathrm{P}_{\mathrm{s}}\right)=\mathrm{P}_{\text {sref }}-\mathrm{P}_{\mathrm{s}} \\
& \mathrm{S}\left(\dot{\mathrm{P}}_{\mathrm{S}}\right)=\mathrm{P}_{\text {sref }}-\dot{\mathrm{P}}_{\mathrm{S}}
\end{aligned}
$$

We replace $\dot{P}_{s}$ by its expression as well as $\dot{I}_{r q}$, we get:

$$
\begin{aligned}
& S\left(\dot{P}_{S}\right)=P_{s r e f}^{\cdot}+V_{s} \cdot \frac{M}{L_{s}} \cdot\left(\frac{V_{r q}}{L_{r} \cdot \sigma}-\frac{R_{r}}{L_{r} \cdot \sigma} \cdot I_{r q}-\omega_{r} \cdot \frac{M \cdot V_{s}}{L_{s} \cdot L_{r} \cdot \sigma \cdot \omega_{s}}\right) \\
& S\left(\dot{P}_{S}\right)=P_{s r e f}+V_{s} \cdot \frac{M}{L_{s}} \cdot\left(\frac{V_{r q e q}+V_{r q n}}{L_{r} \cdot \sigma}-\frac{R_{r}}{L_{r} \cdot \sigma} \cdot I_{r q}-\omega_{r} \cdot \frac{M \cdot V_{S}}{L_{s} \cdot L_{r} \cdot \sigma \cdot \omega_{s}}\right)
\end{aligned}
$$

In sliding mode:

$$
\begin{aligned}
& S\left(P_{s}\right)=0 \\
& S\left(P_{s}\right)=0 \\
& V_{\text {rqn }}=0 \\
& V_{\text {rqeq }}=-L_{s} \cdot L_{r} \cdot \frac{\sigma}{M \cdot V_{s}} \cdot P_{\text {sref }}+\left(R_{r} \cdot I_{r q}+L_{r} \cdot \sigma \cdot I_{r d}+\omega_{r} \cdot M \cdot \frac{V_{s}}{L_{s} \cdot \omega_{s}}\right)
\end{aligned}
$$

The control is given $V_{\text {rqn }}$ by:

$$
\mathrm{V}_{\mathrm{rqn}}=\mathrm{K}_{\mathrm{s}} \cdot \operatorname{sat}\left(\mathrm{S}\left(\mathrm{P}_{\mathrm{s}}\right)\right.
$$

With: $K_{s}$ : Positive gain

\section{REACTIVE POWER CONTROL SURFACE}

With the same method as the active power, we find:

$$
\begin{aligned}
& \mathrm{S}\left(\mathrm{Q}_{\mathrm{s}}\right)=\mathrm{e}\left(\mathrm{Q}_{\mathrm{s}}\right)=\mathrm{Q}_{\text {sref }}-\mathrm{Q}_{\mathrm{s}} \\
& \mathrm{S}\left(\dot{\mathrm{Q}}_{\mathrm{s}}\right)=\mathrm{Q}_{\text {sref }}-\dot{Q}_{\mathrm{s}}
\end{aligned}
$$

We replace $\dot{Q}_{s}$ by its expression as well as $\dot{I}_{r d}$, we get:

$$
\mathrm{S}\left(\dot{\mathrm{Q}}_{\mathrm{s}}\right)=\mathrm{Q}_{\mathrm{sref}}+\mathrm{V}_{\mathrm{s}} \cdot \frac{\mathrm{M}}{\mathrm{L}_{\mathrm{s}}} \cdot\left(\frac{\mathrm{V}_{\mathrm{rd}}}{\mathrm{L}_{\mathrm{r}} \cdot \sigma}-\frac{\mathrm{R}_{\mathrm{r}}}{\mathrm{L}_{\mathrm{r}} \cdot \sigma} \cdot \mathrm{I}_{\mathrm{rd}}\right.
$$

By replacing the expression of $V_{r d}$ with $V_{r d} e q+V_{r d n}$ we obtain:

$$
\mathrm{S}\left(\dot{\mathrm{Q}}_{\mathrm{s}}\right)=\mathrm{Q}_{\mathrm{sref}}+\mathrm{V}_{\mathrm{s}} \cdot \frac{\mathrm{M}}{\mathrm{L}_{\mathrm{s}}} \cdot\left(\frac{\mathrm{V}_{\mathrm{rdeq}}+\mathrm{V}_{\mathrm{rdn}}}{\mathrm{L}_{\mathrm{r}} \cdot \sigma}-\frac{\mathrm{R}_{\mathrm{r}}}{\mathrm{L}_{\mathrm{r}} \cdot \sigma} \cdot \mathrm{I}_{\mathrm{rd}}-\omega_{\mathrm{r}} \cdot \mathrm{I}_{\mathrm{rq}}\right.
$$

In sliding mode:

$$
\begin{aligned}
& \mathrm{S}\left(\mathrm{Q}_{\mathrm{s}}\right)=0 \\
& \mathrm{~S}\left(\dot{\mathrm{Q}}_{\mathrm{s}}\right)=0 \\
& \mathrm{~V}_{\mathrm{rdn}}=0 \\
& V_{\text {rdeq }} \text { becomes: } \\
& \mathrm{V}_{\text {rdeq }}=-\mathrm{L}_{\mathrm{s}} \cdot \mathrm{L}_{\mathrm{r}} \cdot \frac{\sigma}{\mathrm{M} \cdot \mathrm{V}_{\mathrm{s}}} \cdot \mathrm{Q}_{\mathrm{sref}}+\mathrm{R}_{\mathrm{r}} \cdot \mathrm{I}_{\mathrm{rd}}-\mathrm{L}_{\mathrm{r}} \cdot \sigma \cdot \mathrm{I}_{\mathrm{rq}} \cdot \omega_{\mathrm{r}}
\end{aligned}
$$


and discontinuous control $V_{r d n}$ is given by:

$$
\mathrm{V}_{\mathrm{rdn}}=\mathrm{K}_{\mathrm{d}} \cdot \operatorname{sat}\left(\mathrm{S}\left(\mathrm{Q}_{\mathrm{s}}\right)\right.
$$

with: $K_{d}$ : Positive gain

\section{SLIDING FUZZY MOD CONTROL}

The sliding mode control maintains robustness and improves system performance. However, the command switching term produces a chattering phenomenon which is its main flaw. overcome this problem, we propose the model that combines between fuzzy logic control "FLC" and sliding mode control "SMC" [30]. The sliding mode control law is defined by the control strategy, which depends on the sign of the error if it is negative, and then the system output is driven in the positive direction.

For this the term $\mathrm{K}_{\mathrm{d}}$. $\operatorname{sat}\left(\mathrm{S}\left(\mathrm{U}_{\mathrm{n}}\right)\right.$ can be replaced by a fuzzy controller. This controller has an input $\mathrm{S}(\mathrm{x})$ and an output $\mathrm{U}_{\mathrm{n}}$ and its rule base is used to establish a connection between $\mathrm{S}(\mathrm{x})$ and $\mathrm{U}_{\mathrm{n}}$. This is interpreted by the rules of the form (If... Then) [31], [32]. We design for this purpose a command by fuzzy sliding mode to control the active and reactive powers as presented in Figure 8 The basic input and output linguistic variables of the fuzzy control rule are presented in Figure 9.
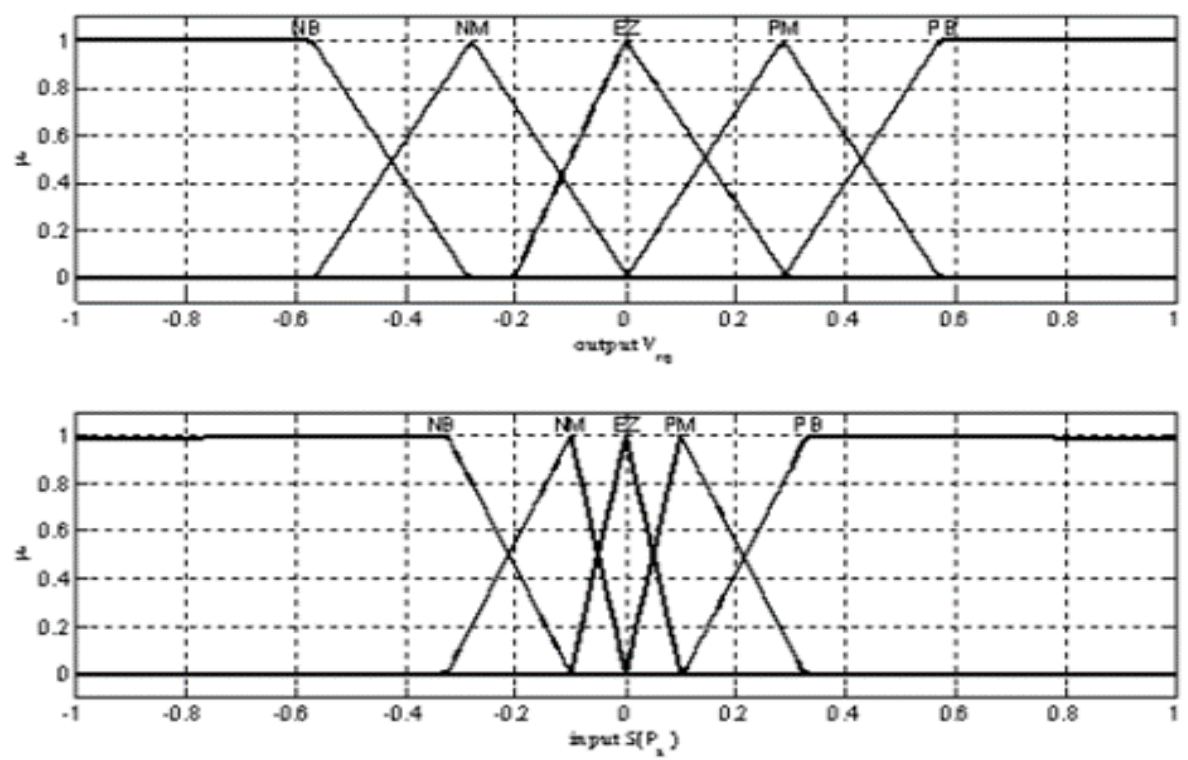

Figure 8. Membership functions defined for sliding fuzzy control of reactive power

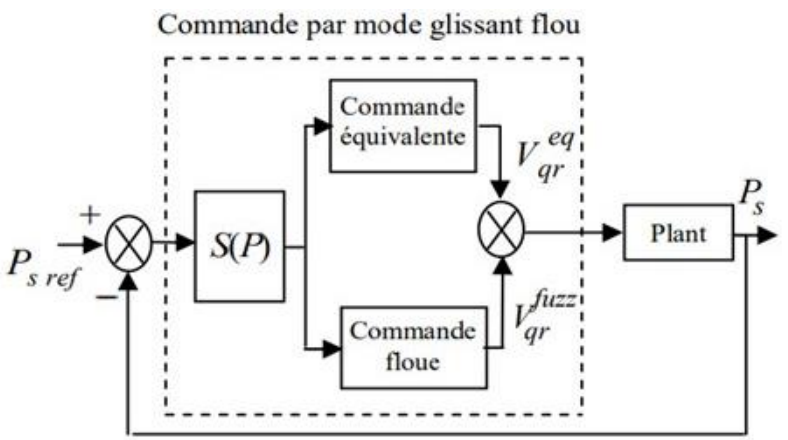

Figure 9. Active power control principal diagram by fuzzy sliding mode 
In this section, the FLC fuzzy command is introduced to replace the $K_{d}$. sat $\left(S\left(U_{n}\right)\right.$ function, good steady-state dynamics can be obtained applying fuzzy logic to the DFIG speed command by combining it with the sliding mode command. The verification of the advantages of this new fuzzy sliding mode command will be carried out by simulation. The speed and rotor flux regulators are replaced by a sliding-fuzzy mode regulator.

\section{SIMULATION RESULTS}

In purpose to present the evaluation of the performance of the new hybrid fuzzy sliding mode control SFMC, we will expose the simulations carried out on an asynchronous machine with double power supply, Figure 10 represents the block diagram of the simulation of the principle of the fuzzy sliding mode control applied to DFIG, replacing the sign $\left(\mathrm{S}_{\mathrm{w}}\right)$ function with a crazy controller.

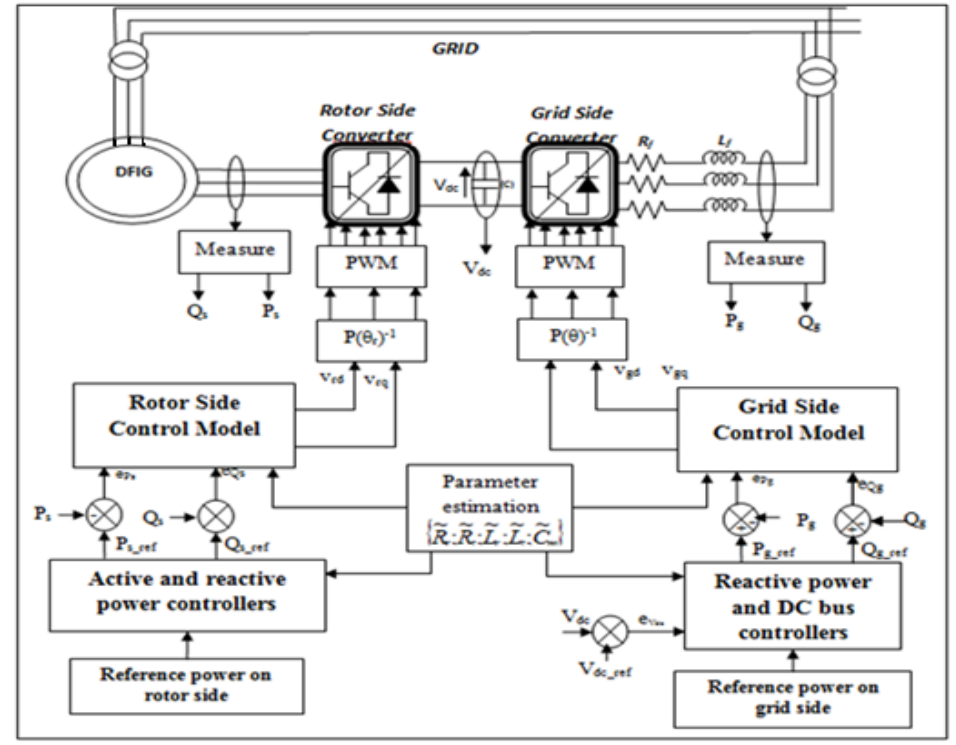

Figure 10. Sliding mode control applied to DFIG

\subsection{Performance test}

We will study and analyze the response of the DFIG for a wind profile that we choose to be random. In order to improve the quality of the electrical energy injected into the network, we are going to set the reactized power to zero. (Qs_ref $=0$ Var). The wind profile used in the simulations presented is a real wind profile. The results of the responses of the fuzzy logic mode sliding control of the DFIG are represented in Figure 11 (see Appendix) shows the chosen winds are that of the Tanger region located in the north of Morocco. The Figure 12 shows THD for the rotor current $6.29 \%$ and $0.16 \%$ for the stator current (according to standard IEEE519-2014).

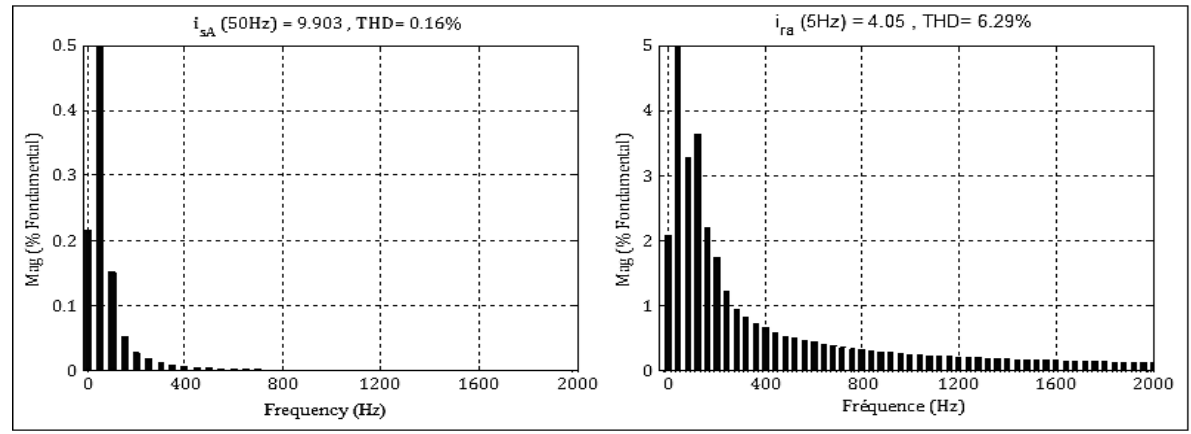

Figure 12. THD of currents at variable wind speed 


\subsection{Robustness test}

We are going to make some modifications to the internal parameters of the DFIG to verify the robustness and stability of the fuzzy sliding mode control on active and reactive power regulation. On this, the tests carried out are carried out on the basis of an increase and decrease of the parameters of the machine such as the stator, the resistances and the inductances of the rotor. Thus, the dynamic behavior of the system is represented in Figure 13.
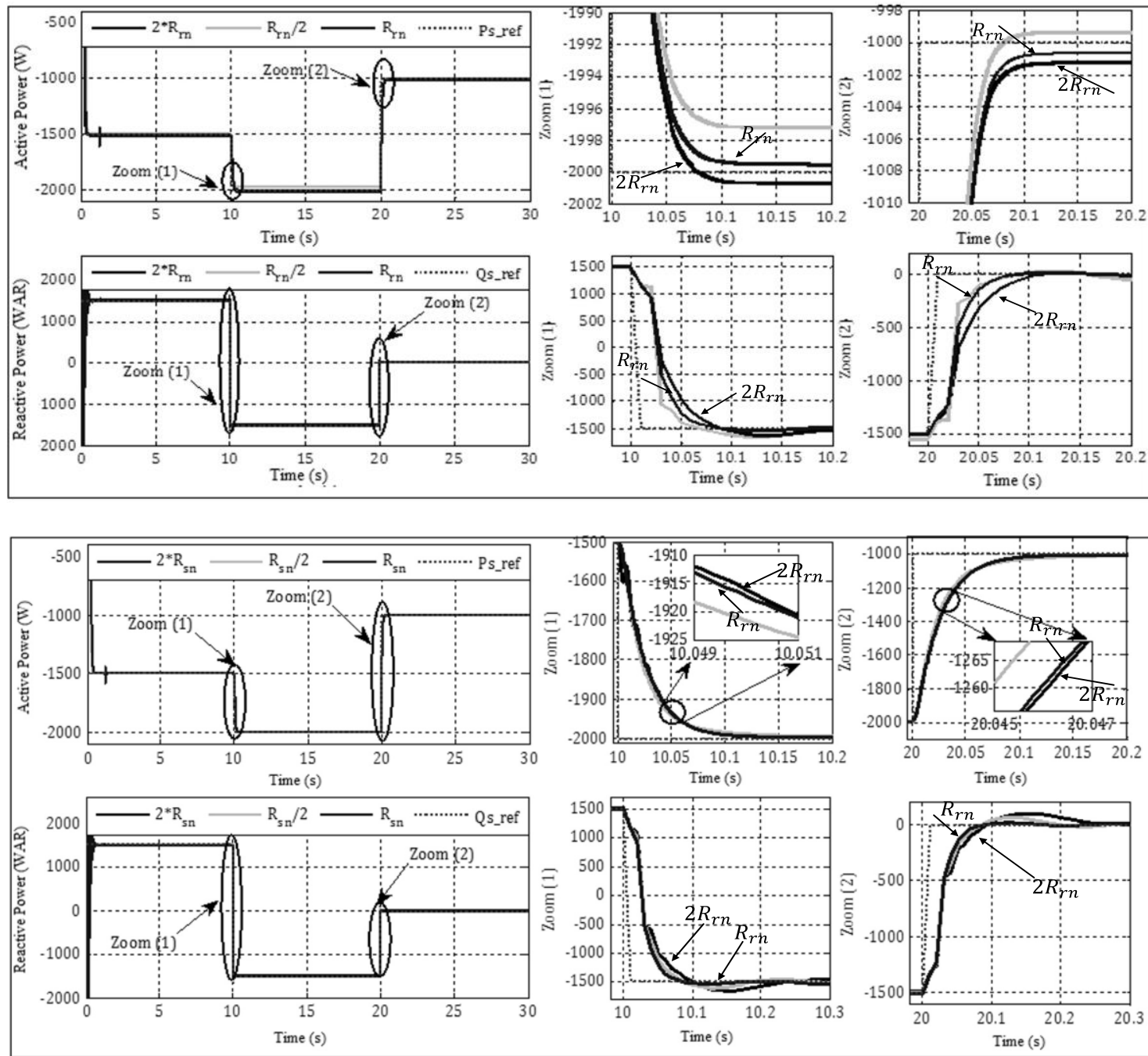

Figure 13. Robustness test during resistance variation

However, the changes applied to the resistances of the stator and the rotor cause a slight increase in the response time, which is detected in Figure 13, we therefore notice that the simulation results show a great robustness of the fuzzy-sliding mode command with respect to the parametric variations of the DFIG. This is justified by the good follow-up of the power setpoints, with almost the same response time at start-up. It always maintains the decoupling between active and reactive power. This performance is showing in Table 1.

Table 1. Performance comparison

\begin{tabular}{cccccc}
\hline Publication & Technic Control & Efficiency & Error & Cos $\varphi$ & « Robustness » \\
\hline$[10]$ & Adaptive Controller & 93.5 & $0,15 \%$ & 0.997 & Moderate-high \\
& Fuzzy Controller & 93.99 & $0,14 \%$ & 0.974 & Moderate-high \\
[4] & classical DTC & 92.13 & $0,32 \%$ & 0.983 & Moderate-high \\
& PI-DTC & 92.07 & $0,12 \%$ & 0.978 & Moderate-high \\
[3] & Sliding mode Control & 94.82 & $0,2 \%$ & 0.972 & Low \\
Proposal technique & Fuzzy-SMC Control & 98.99 & $0,12 \%$ & 0.995 & High \\
\hline
\end{tabular}




\section{CONCLUSION}

In this article, we have presented the control of a wind energy recovery system equipped with a doubly fed induction generator. Firstly, a generator model was proposed, and then a fuzzy sliding mode control strategy of the asynchronous generator allowing independent power control was proposed. Fuzzy sliding mode active and reactive power regulators have been proposed and tested. The simulation results enabled us to assess the performance and robustness of the fuzzy sliding mode control. Thanks to the response characteristics, good performance is observed even in the presence of set point variations. The pursuit of power is without overshoot. Decoupling, stability and convergence towards equilibrium are ensured. In addition, this setting has the advantage of being easily implemented in a computer control.

\section{APPENDIX}
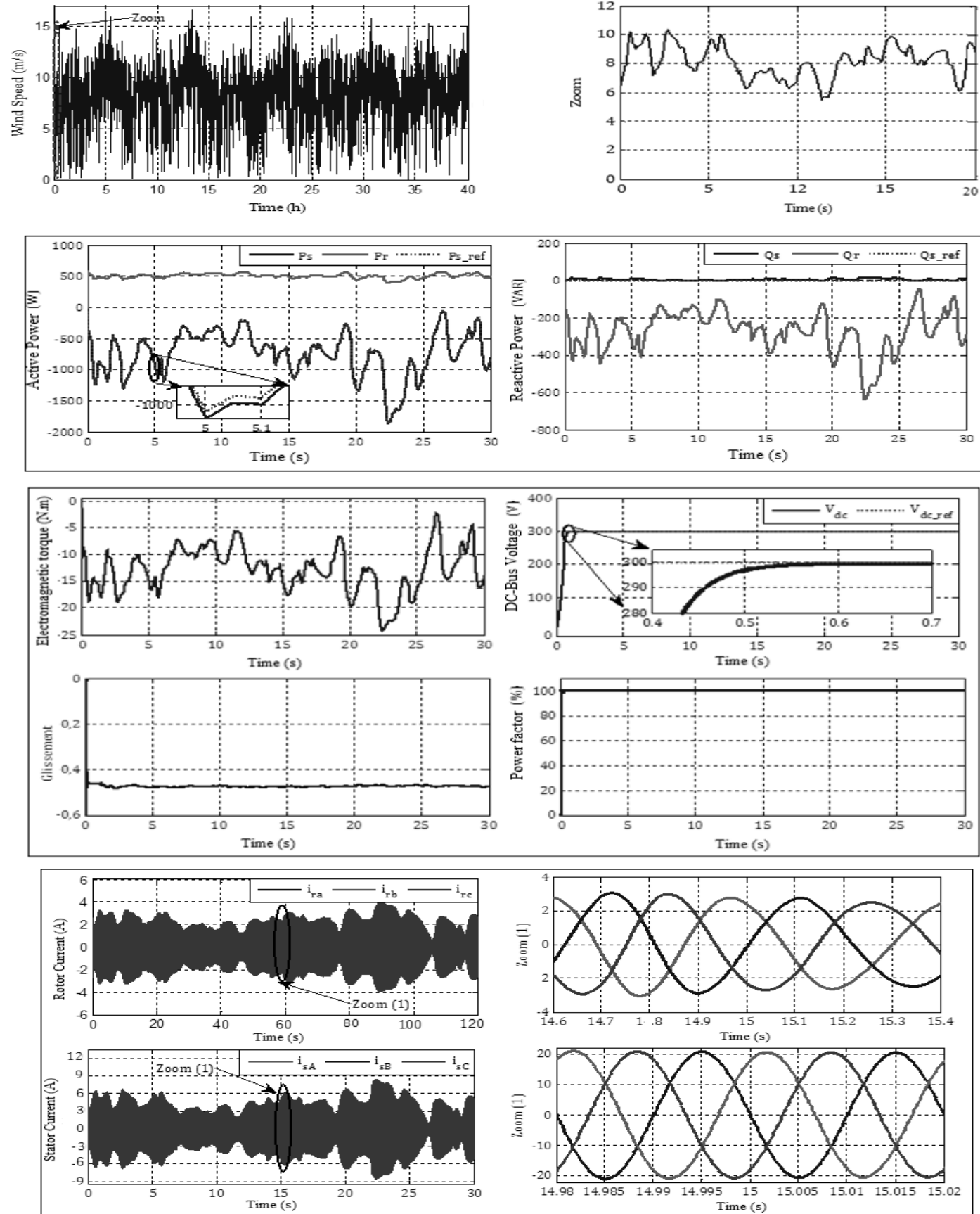

Figure 11. Performance test of the SFMC applied to the DFIG 


\section{REFERENCES}

[1] B. Bossoufi, M. Karim, A. Lagrioui, M. Toussi, and A. Derouich, "Observer backstepping control of DFIG-Generators for wind turbines variable-speed: FPGA-based implementation,” Renewable Energy, vol. 81, pp. 903-917, 2015, doi: 10.1016/j.renene.2015.04.013.

[2] A. Zemmit, S. Messalti and A. Harrag, "A new improved DTC of doubly fed induction machine using GA-based PI controller," Ain Shams Engineering Journal, vol. 9, no. 4, pp. 1877-1885, 2018, doi: 10.1016/j.asej.2016.10.011.

[3] E. M. Youness et a., "Implementation and validation of backstepping control for PMSG wind turbine using dSPACE controller board," Energy Report, vol. 5, pp. 807-821, 2019, doi: 10.1016/j.egyr.2019.06.015.

[4] I. E. Karaoui, M. Maaroufi, and B. Bossoufi, "Robust power control methods for wind turbines using DFIG-generator," International Journal of Power Electronics and Drive Systems, vol. 10, no. 4, pp. 2101-2117, 2019, doi: 10.11591/ijpeds.v10.i4.2101-2117.

[5] D. Seyoum, M. F. Rahman and C. Grantham, "Terminal voltage control of a wind turbine driven isolated induction generator using stator oriented field control," Eighteenth Annual IEEE Applied Power Electronics Conference and Exposition, 2003, vol. 2, pp. 846-852, doi: 10.1109/APEC.2003.1179315.

[6] Z. Zhang, Y. Zhao, W. Qiao and L. Qu, "A Space-Vector-Modulated Sensorless Direct-Torque Control for Direct-Drive PMSG Wind Turbines," IEEE Transactions on Industry Applications, vol. 50, no. 4, pp. 2331-2341, doi: 10.1109/TIA.2013.2296618.

[7] B. Beltran, M. E. H. Benbouzid and T. Ahmed-Ali, "Second-Order Sliding Mode Control of a Doubly Fed Induction Generator Driven Wind Turbine," IEEE Transactions on Energy Conversion, vol. 27, no. 2, pp. 261-269, 2012, doi: 10.1109/TEC.2011.2181515.

[8] B. Yang, T. Yu, H. Shu, J. Dong and L. Jiang, "Robust Sliding-mode Control of Wind Energy Conversion Systems for Optimal Power Extraction via Nonlinear Perturbation Observers," Applied Energy, vol. 210, pp. 711-723, 2018, doi: 10.1016/j.apenergy.2017.08.027.

[9] B. Beltran, T. Ahmed-Ali and M. E. H. Benbouzid, "High-Order Sliding-Mode Control of Variable-Speed Wind Turbines," IEEE Transactions on Industrial Electronics, vol. 56, no. 9, pp. 3314-3321, 2009, doi: 10.1109/TIE.2008.2006949.

[10] I. E. Karaoui, M. Maaroufi and H. Chaikhy "Contribution to improving the DFIG Control using Multi-level inverter," World Academy of Science, Engineering and Technology International Journal of Energy and Power Engineering vol. 13, no. 6, pp. 385$388,2019$.

[11] I. Matraji, A. A. Durra and R. Errouissi, "Design and experimental validation of enhanced adaptive second-order SMC for PMSGbased wind energy conversion system," International Journal of Electrical Power \& Energy Systems, vol. 103, pp. 21-30, 2018, doi: 10.1016/j.ijepes.2018.05.022Get rights and content.

[12] E. Dogan and F. Seker, "The influence of real output, renewable and non-renewable energy, trade and financial development on carbon emissions in the top renewable energy countries," Renewable and Sustainable Energy Reviews, vol. 60, pp. 1074-1085, 2016, doi: 10.1016/j.rser.2016.02.006.

[13] B. Bossoufi et al., "Rooted Tree Optimization for Backstepping Power Control of DFIG Wind Turbine: dSPACE Implementation," IEEE Access, vol. 9, no 1. pp. 26512-26522, 2021.

[14] M. E. Mahfoud, B. Bosssoufi, N. E. Ouanjli, M. Said and M. Taoussi, "Improved Direct Torque Control of Doubly Fed Induction Motor Using Space Vector Modulation,” International Journal of Intelligent Engineering and Systems, vol. 14, no. 3, pp. 177-188, 2021.

[15] Y. Errami, A. Obbadi, S. Sahnoun, M. Ouassaid, Mohamed and M. Maaroufi, "Power extraction control of variable speed wind turbine systems based on direct drive synchronous generator in all operating regimes," Journal of Electrical and Computer Engineering, vol. 2018, ID. 3837959, pp. 1-18, 2018

[16] S. Boubzizi, H. Abid, A. El hajjaji, and M. Chaabane, "Comparative study of three types of controllers for DFIG in wind energy conversion system," Prot. Control Mod. Power Syst., vol. 3, no. 1, pp. 1-12, 2018, doi: 10.1186/s41601-018-0096-y.

[17] L. Yang, T. Liu, and D. J. Hill, "Distributed MPC-based frequency control for multi-area power systems with energy storage," Electr. Power Syst. Res., vol. 190, no. October 2019, p. 106642, 2021, doi: 10.1016/j.epsr.2020.106642.

[18] D. Zhou and F. Blaabjerg, "Bandwidth oriented proportional-integral controller design for back-to-back power converters in DFIG wind turbine system," IET Renew. Power Gener., vol. 11, no. 7, pp. 941-951, 2017, doi: 10.1049/iet-rpg.2016.0760.

[19] F. Mazouz, S. Belkacem, I. Colak, S. Drid, and Y. Harbouche, "Adaptive direct power control for double fed induction generator used in wind turbine," Int. J. Electr. Power Energy Syst., vol. 114, no. June 2019, p. 105395, 2020, doi: 10.1016/j.ijepes.2019.105395.

[20] S. Vazquez et al., "Model predictive control: A review of its applications in power electronics," IEEE Ind. Electron. Mag., vol. 8, no. 1, pp. 16-31, 2014, doi: 10.1109/MIE.2013.2290138.

[21] P. Segovia, V. Puig, E. Duviella, and L. Etienne, "Distributed model predictive control using optimality condition decomposition and community detection," J. Process Control, vol. 99, pp. 54-68, 2021, doi: 10.1016/j.jprocont.2021.01.007.

[22] B. Jain, S. Jain, and R. K. Nema, "Control strategies of grid interfaced wind energy conversion system: An overview," Renew. Sustain. Energy Rev., vol. 47, pp. 983-996, 2015, doi: 10.1016/j.rser.2015.03.063.

[23] B. Manale, B. Badre, A. A. Hala, T. Mohammed, L. Ahmed, and L. Petru, "DEADBEAT control applied towind power system," 2020 5th Int. Conf. Renew. Energies Dev. Countries, REDEC 2020, vol. 5, no. 2, 2020, doi: 10.1109/REDEC49234.2020.9163601.

[24] A. J. S. Filho and E. Ruppert, "Modeling and Designing a Deadbeat Power Control for Doubly-Fed Induction Generator," no. January 2016, 2011, doi: 10.5772/16496.

[25] H. Gholami-Khesht and M. Monfared, "Deadbeat direct power control for grid connected inverters using a full-order observer," 2015 4th Int. Conf. Electr. Power Energy Convers. Syst. EPECS 2015, 2015, pp. 0-4, doi: 10.1109/EPECS.2015.7368540.

[26] S. E. Rhaili, A. Abbou, S. Marhraoui, R. Moutchou and N. El Hichami, "Robust Sliding Mode Control with Five Sliding Surfaces of Five-Phase PMSG Based Variable Speed Wind Energy Conversion System," International Journal of Intelligent Engineering and Systems, vol. 13, no. 4, pp. 346-357, 2020

[27] H. H. H. Mousa, A. R. Youssef, and E. E. M. Mohamed, "Optimal Power Extraction Control Schemes for Five-Phase PMSG Based Wind Generation Systems,” Engineering Science and Technology, an International Journal, vol. 23, no. 1, pp. 144-155, 2020.

[28] S. E. Rhaili et al., "Mawimum power extraction of five-phase PMSG WECS by adopting and improved fractional order sliding mode strategy," no. September, pp. 55-74, 2021, doi: 10.17605/OSF.IO/HWND6

[29] L. Yang, T. Liu, and D. J. Hill, "Distributed MPC-based frequency control for multi-area power systems with energy storage," Electr. Power Syst. Res., vol. 190, no. October 2019, p. 106642, 2021, doi: 10.1016/j.epsr.2020.106642. 
[30] D. Zhou and F. Blaabjerg, "Bandwidth oriented proportional-integral controller design for back-to-back power converters in DFIG wind turbine system,” IET Renew. Power Gener., vol. 11, no. 7, pp. 941-951, 2017, doi: 10.1049/iet-rpg.2016.0760.

[31] F. Mazouz, S. Belkacem, I. Colak, S. Drid, and Y. Harbouche, "Adaptive direct power control for double fed induction generator used in wind turbine," Int. J. Electr. Power Energy Syst., vol. 114, no. June 2019, p. 105395, 2020, doi: 10.1016/j.ijepes.2019.105395.

[32] S. Vazquez et al., "Model predictive control: A review of its applications in power electronics," IEEE Ind. Electron. Mag., vol. 8, no. 1, pp. 16-31, 2014, doi: 10.1109/MIE.2013.2290138.

\section{BIOGRAPHIES OF AUTHORS}

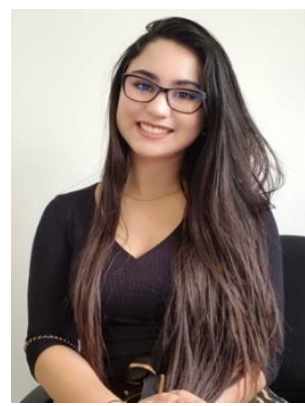

Imane El Karaoui (D) 8d SC P was born in Rabat, Morocco, in 1991. She received the Engineer Diploma from the faculty of science and technology "Faculté des sciences et Technique" FSTS, University Hassan 1er in Settat, Morocco in 2014 and the PhD researcher in the Electrical Engineering Department of the Mohammadia School of Engineers "Ecole Mohammadia dIngénieurs" EMI, Rabat, Morocco, and currently working as a state engineer at the Ministry of Energy Transition and Sustainable Development in Morocco. She can be contacted at email: elkaraoui.imane@gmail.com.

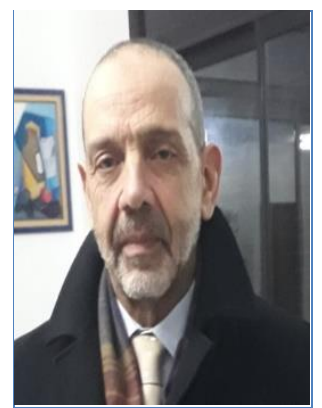

Mohamed Maaroufi (D) SC P was born in Marrakech, Morocco, in 1955. He received the Engineer Diploma from the Mohammadia School of Engineers "Ecole Mohammadia d'Ingénieurs" EMI, University Mohammed V in Rabat, Morocco in 1979 and the PhD from the "Université de Liège", Liège, Belgium in 1990. He joined the Electrical Engineering Department of "Ecole Mohammadia d'Ingénieurs" EMI, Rabat, Morocco, where is currently Professor and Researcher. His current research interests includ Electric Network, Smart Grid, Renewable Energy (mainly PV and Wind), Electric Drives, Power Systems and Energy Efficiency. The Scientific Research gives more than fifteen theses and more than a two hundred papers in Conferences and Journals. He can be contacted at email: maaroufi@emi.ac.ma.

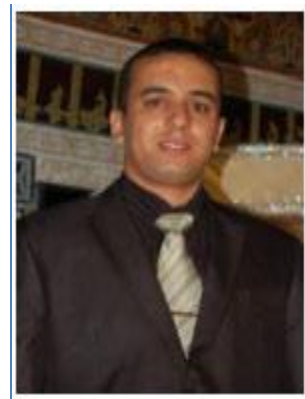

Badre Bossoufi (iD IS SC P (Graduate Student Member, IEEE) was born in Fez, Morocco, in 1985. He received the Ph.D. degree in electrical engineering from the Faculty of Sciences, Sidi Mohammed Ben Abdellah University, Fez, Morocco, and the Ph.D. degree from the Faculty of Electronics and Computer, The University of Pitesti, Romania, and the Department of Electrical Engineering, Montefiore Institute, Liège, Belgium, in 2012. He was a Professor of Electrical Engineering with the Faculty of Sciences, Sidi Mohamed Ben Abdellah University. His research interests include static converters, electrical motor drives, power electronics, smart grid, renewable energy, and arti_cial intelligent. He can be contacted at email: badre_isai@hotmail.com. 